\title{
Características de Plantas de Arroz e a Habilidade Competitiva COM Plantas Daninhas ${ }^{1}$
}

\author{
Characteristics of Rice Plants and their Competitive Ability with Weeds
}

\author{
BALBINOT JR., A.A. ${ }^{2}$, FLECK, N.G. ${ }^{3}$, BARBOSA NETO, J.F. ${ }^{3}$ e RIZZARDI, M.A. ${ }^{4}$
}

\begin{abstract}
RESUMO - O potencial competitivo das plantas pelos recursos de crescimento do meio é afetado por suas características morfofisiológicas. Ainda não há consenso sobre qual característica da planta de arroz irrigado é mais importante na determinação da sua capacidade competitiva com as plantas daninhas. Este trabalho teve como objetivo identificar características da planta de arroz irrigado por inundação que mais contribuam na competitividade da cultura. Nesse sentido, conduziu-se um experimento em campo no ano agrícola 2000/01, em Cachoeirinha-RS, com oito genótipos de arroz, cultivados na presença ou ausência do cultivar de arroz EEA 406, simulando infestação de arroz-vermelho. Foram avaliadas características das plantas de arroz na condição de ausência de competição e, por ocasião da colheita, determinou-se a redução de rendimento de grãos para cada genótipo, decorrente da competição com as plantas daninhas. Por meio de análise de regressão linear múltipla e correlação linear simples, determinou-se que a habilidade dos cultivares em sombrear o solo aos 60 dias após semeadura (DAS) foi a variável mais relacionada com o potencial competitivo, e que essa característica esteve especialmente associada com o acúmulo de massa aérea pelas plantas de arroz aos 15 DAS.
\end{abstract}

Palavras-chave: competição, interferência, arroz-vermelho, sombreamento do solo, velocidade de crescimento.

\begin{abstract}
Competitive hability of plants for the use of environmental resources is affected by their morpho-physiological characteristics. There is no agreement on which rice plant characteristic is the most important in determining its competitive ability against weeds. This research aimed to identify flooded rice plant characteristics that contribute the most to its competitiveness. Thus, a field experiment was carried out during the 2000/01 growing season in Cachoeirinha, RS, to compare the behavior of eight rice genotypes, grown in the absence or presence of the EEA 406 rice genotypes, simulating a red rice infestation. Rice plant characteristics in the absence of competition were evaluated and at harvesting time, grain yield decrease was determined for each rice genotype, due to competition effect. The analysis of multiple linear regression and simple linear correlation showed that the ability of a cultivar to shadow the soil 60 days after seeding (DAS) was the variable more closely related to its competitive potential, and that this characteristic was especially associated with rice plant shoot matter accumulation at 15 DAS.
\end{abstract}

Key words: competition, interference, red rice, soil coverage, growth rate.

1 Recebido para publicação em 11.4.2002 e na forma revisada em 11.8.2003.

Esta pesquisa recebeu apoio financeiro da Fundação de Amparo à Pesquisa do Estado do Rio Grande do Sul (FAPERGS), processo $n^{\circ} 00 / 2660.0$.

2 Eng.-Agr., M.S., Pesquisador da Epagri/Estação Experimental de Canoinhas, Caixa Postal 216, 89460-000 Canoinhas-SC, $<$ balbinot@epagri.rct-sc.br; ${ }^{3}$ Eng.-Agr., Ph.D., Professor do Departamento de Plantas de Lavoura da Faculdade de Agronomia da Universidade Federal do Rio Grande do Sul - UFRGS, Bolsista do CNPq, Caixa Postal 776, 91501-970 Porto Alegre-RS, $<$ fleck@ufrgs.br>; ${ }^{4}$ Eng.-Agr., D.S., Professor da Faculdade de Agronomia da Universidade de Passo Fundo - UPF.

Planta Daninha, Viçosa-MG, v.21, n.2, p.165-174, 2003 


\section{INTRODUÇÃO}

No Sul do Brasil, o arroz-vermelho (Oryza sativa) constitui-se na principal invasora de áreas cultivadas com arroz irrigado por inundação (Agostinetto et al., 2001). Por pertencerem à mesma espécie, o arroz daninho e o cultivado apresentam elevada similaridade morfofisiológica, o que dificulta o controle seletivo, fazendo-se necessário utilizar métodos culturais de controle, dentre os quais se destaca a utilização de cultivares que detêm elevada capacidade competitiva.

Nos últimos anos, pesquisas relacionadas à habilidade competitiva de cultivares com plantas daninhas vêm ganhando importância, principalmente porque a adoção de genótipos com alta competitividade constitui-se em prática cultural de reduzido custo e impacto ambiental. Grande parte dos estudos sobre interferência de plantas daninhas em culturas considera somente a ocorrência e o impacto da competição na produtividade destas. Número escasso de pesquisas tem sido realizado para quantificar a importância de características da planta cultivada na determinação de sua habilidade competitiva com plantas daninhas (Radosevich et al., 1997).

O incremento da capacidade competitiva de plantas é atribuído a emergência precoce, elevado vigor de plântulas, rapidez de expansão foliar, formação de dossel denso, elevada altura de planta, ciclo de desenvolvimento longo e rápido crescimento do sistema radicular (Seibert \& Pearce, 1993; Roman et al., 1999; Seefeldt et al., 1999; Bennett \& Shaw, 2000; Horak \& Loughin, 2000). Plantas portadoras de elevada velocidade de emergência e de crescimento inicial possuem prioridade na utilização dos recursos do meio e, por isso, geralmente levam vantagem na utilização destes (Firbank \& Watkinson, 1985). De outro modo, elevada altura de planta e formação de dossel compacto por parte da cultura relacionam-se à capacidade de sombreamento às plantas daninhas, reduzindo a disponibilidade de radiação solar à fotossíntese das infestantes (Garrity et al., 1992). Adicionalmente, cultivares de culturas anuais com ciclo tardio, em geral, iniciam a fase reprodutiva quando as plantas daninhas estão cessando seu ciclo e, por isso, os recursos disponiveis se revertem, na maioria das vezes, para a cultura.
Devido às interações de características de planta na determinação da competitividade dos vegetais, torna-se dificil identificar aquelas que realmente se associam com elevada capacidade competitiva. Em arroz, por exemplo, ainda não há consenso sobre qual ou quais características de planta influenciam a habilidade da cultura em competir com plantas daninhas (Ni et al., 2000). Esse fato dificulta a seleção de cultivares mais hábeis em competir com espécies infestantes, tornando-se um entrave para o melhoramento quando se visa elevar o patamar de competitividade das culturas. Portanto, é necessário definir, para cada cultura, as características de planta que possuam maior expressividade em dotar os cultivares de habilidade superior no processo de competição com espécies daninhas.

Segundo Jannink et al. (2000), em soja, a velocidade de ganho em altura confere maior competitividade com plantas daninhas, embora altura de soja não esteja correlacionada com interceptação de luz pelo dossel da cultura. Foi postulado que o incremento em área foliar e o sombreamento rápido da área são características importantes para se definir o potencial competitivo dos vegetais (Satorre $\&$ Snaydon, 1992). Entretanto, nos casos em que predominam inter-relações abaixo da superfície do solo, o crescimento rápido do sistema radicular pode ser fator fundamental para o sucesso competitivo das plantas, garantindo-lhes utilização precoce de água e nutrientes (Seibert \& Pearce, 1993).

Em pesquisa com arroz irrigado por inundação, Ni et al. (2000) determinaram, através de análise de regressão linear múltipla, que a velocidade de acúmulo de massa na parte aérea pela cultura até o início do afilhamento (cerca de 35 dias após a semeadura do arroz) foi a variável mais importante na predição do acúmulo de massa pelas plantas daninhas presentes na área de cultivo. Esta variável foi fortemente correlacionada com formação de dossel com elevado potencial de captação de energia radiante, reduzindo a disponibilidade desse recurso às infestantes.

A hipótese desta pesquisa é de que há variação na habilidade competitiva entre cultivares de arroz irrigado por inundação, sendo possivel identificar características que sejam 
mais importantes na definição da capacidade competitiva da cultura. Diante do exposto, este trabalho teve como objetivo identificar características morfológicas e fisiológicas envolvidas na definição da capacidade competitiva de cultivares de arroz irrigado por inundação, a fim de orientar trabalhos de melhoramento vegetal na seleção de genótipos superiores para competir com plantas concorrentes.

\section{MATERIAL E MÉTODOS}

O experimento foi conduzido em campo, durante o ano agrícola 2000/2001, na Estação Experimental do Arroz (EEA), pertencente ao Instituto Rio-Grandense do Arroz (IRGA), em Cachoeirinha-RS. O preparo do solo foi realizado através do método convencional, compreendendo operações de aração e de gradagem.

Os tratamentos testados foram dispostos segundo o delineamento experimental inteiramente casualizado, em esquema fatorial $(8 \times 2)$, com quatro repetições. Cada unidade experimental apresentou área total de $4 \mathrm{~m}^{2}(2 \times 2 \mathrm{~m})$ e área útil de 2,56 $\mathrm{m}^{2}(1,6 \times 1,6 \mathrm{~m})$. Avaliaramse, como um dos fatores, oito cultivares de arroz: Bluebelle, BRS Ligeirinho, El Paso L 144, IAS 12-9 Formosa, IR 841, IRGA 418, IRGA 421 e XL 6. Esses genótipos foram submetidos a duas situações de competição, ausência e presença de simuladora de infestação de arroz-vermelho, no caso o cultivar de arroz EEA 406, estabelecido na densidade média de 30 plantas $\mathrm{m}^{-2}$. Este cultivar apresenta arquitetura de planta equivalente à do arroz-vermelho.

A densidade de semeadura foi ajustada para cada cultivar com base no poder germinativo das sementes, obtido em laboratório, almejando-se estabelecer densidade de 300 plantas $\mathrm{m}^{-2}$. Contudo, a densidade média alcançada foi de aproximadamente 270 plantas $\mathrm{m}^{-2}$. A simuladora do arroz-vermelho foi semeada em linhas perpendiculares às dos cultivares testados, ambas no espaçamento de $20 \mathrm{~cm}$ entre linhas.

Foram avaliados as seguintes características dos cultivares de arroz quando na ausência da simuladora:

Velocidade de emergência (VE): foi avaliada através da contagem das plântulas emergidas (com coleóptilo maior que $1,5 \mathrm{~cm}$ ) aos $6,8,10,12,14$ e 16 dias após semeadura (DAS). A unidade amostrada foi $0,5 \mathrm{~m}$ de fileira por parcela, sempre no mesmo local. Aos 16 DAS, considerou-se completada a fase de emergência. Com esses dados, calculou-se o índice de velocidade de emergência (IVE), por meio da equação sugerida por Popinigis (1977): $\mathrm{IVE}=\mathrm{N}_{1} / \mathrm{D}_{1}+\ldots+\mathrm{N}_{\mathrm{n}} / \mathrm{D}_{\mathrm{n}}$, em que: IVE = índice de velocidade de emergência; $\mathrm{N}_{1}=$ número de plântulas emergidas no primeiro dia; $\mathrm{N}_{\mathrm{n}}=$ número não acumulado de plântulas emergidas; $D_{1}=$ primeiro dia de contagem; e $D_{n}=$ número de dias contados após a semeadura.

Área foliar: foi determinada em laboratório, com auxílio de determinador de área foliar (modelo Area Meter 3100), utilizando cinco plantas por parcela, amostradas aos 15 , 30, 45 e 60 DAS.

Estádio de desenvolvimento do colmo principal: foi observado visualmente em cinco plantas por parcela aos 15, 30, 45 e 60 DAS, utilizando-se escala de desenvolvimento fenológico proposta por Haun (1973).

Altura de planta: foi medida a altura da parte aérea, tomando-se o comprimento desde o nível do solo até o ápice desta, com o limbo foliar distendido; para isso, amostraram-se cinco plantas por parcela aos 15, 30, 45 e 60 DAS.

Massa seca da parte aérea: foi avaliada aos 15, 30, 45 e 60 DAS, através da pesagem de cinco plantas por parcela, após estas serem secas em estufa a $65{ }^{\circ} \mathrm{C}$, até atingirem peso constante.

Cobertura do solo pelas plantas de arroz: foi estimada visualmente por duas pessoas, aos 45 e 60 DAS, utilizando escala de valores percentuais.

Penetração de luz no dossel da cultura: foi determinada aos 70 DAS, utilizando um determinador de área foliar, modelo Licor LAI2000, com sensor Licor LI-190SA. Mediuse a radiação solar incidente acima da comunidade de plantas e, simultaneamente, próximo à superficie do solo. Com esses dados, calculouse a porcentagem da radiação que penetrou no dossel da cultura. As leituras foram obtidas por volta do meio-dia, quando o ângulo solar era próximo de $90^{\circ}$, perpendicularmente à superfície do solo. 
Teor de clorofila nas folhas do arroz: foi determinado aos 50 DAS, utilizando um clorofilômetro, modelo SPAD. A medida foi feita no limbo da última folha expandida, em cinco plantas de arroz por unidade experimental.

Aos 60 DAS avaliou-se a massa seca da parte aérea da simuladora, através da pesagem de cinco plantas por parcela, após estas serem secas em estufa a $65{ }^{\circ} \mathrm{C}$, até atingirem peso constante.

Na ocasião da colheita, foram avaliadas as seguintes variáveis nos cultivares de arroz:

Duração do ciclo: compreendeu o número de dias decorrentes da semeadura dos cultivares até sua respectiva colheita.

Altura final de planta: foram amostradas ao acaso cinco plantas por parcela, nas quais foi medida a distância da superfície do solo até o ápice destas, com o limbo foliar distendido.

Produtividade de grãos: foi realizada colheita manual das panículas de arroz na área útil de cada unidade experimental. Depois disso, as panículas foram trilhadas e os grãos pesados. Os resultados de produtividade dos cultivares foram expressos em $\mathrm{kg} \mathrm{ha}^{-1}$, procedendo-se à uniformização do teor de umidade para $13 \%$ (base úmida). Esta variável foi avaliada nas duas situações de interferência: com e sem presença da simuladora. Com esses dados, calculou-se a porcentagem de redução de produtividade de grãos de cada cultivar em presença da simuladora.

Os dados coletados foram submetidos à análise de regressão linear múltipla, com o objetivo de identificar que caracteristicas de plantas de arroz foram mais relevantes na predição da habilidade dos cultivares em competir com a simuladora de arroz-vermelho. Para isso, considerou-se a redução percentual de produtividade de grãos dos genótipos de arroz, decorrente da interferência exercida pela simuladora, a massa seca da parte aérea acumulada pela simuladora de arroz-vermelho e a cobertura do solo proporcionada pelos cultivares aos 60 DAS como variáveis dependentes no modelo, enquanto as demais características avaliadas constituíram-se em variáveis independentes. Adicionalmente, realizou-se análise de correlação linear simples entre as variáveis pesquisadas. Em ambas as análises adotou-se o nivel de probabilidade de $5 \%$. A análise estatística foi realizada por meio do programa computacional SAS (Sas, 1989).

\section{RESULTADOS E DISCUSSÃO}

As perdas de rendimento de grãos de arroz em decorrência da interferência causada pela simuladora de arroz-vermelho (EEA 406) variaram de $11,5 \%$ no cultivar IR 841 a $41,3 \%$ no cultivar Bluebelle (dados não mostrados), indicando que os genótipos investigados apresentam variação em suas habilidades competitivas. Pela análise de regressão linear múltipla (Tabela 1 e Figura 1), determinou-se que a variável cobertura do solo aos 60 DAS foi a característica que, isoladamente, melhor estimou a habilidade competitiva dos cultivares. Assim, a capacidade dos cultivares de sombrear o solo representou um requisito fundamental para seu sucesso competitivo. A cobertura do solo aos 60 DAS, usada como variável independente no modelo, conseguiu explicar $47 \%$ das variações de redução de produtividade de grãos decorrente da presença da simuladora (Tabela 1) e 64\% das variações de acúmulo de massa seca da parte aérea na simuladora de arroz-vermelho aos 60 DAS (Tabela 2).

Verificou-se tendência de redução linear na perda de rendimento de grãos dos cultivares e na massa aérea acumulada pela simuladora aos 60 DAS, em resposta ao aumento da cobertura do solo proporcionado pelas plantas de arroz aos 60 DAS (Figuras 1 e 2). Esse fato ocorreu porque, em arroz irrigado por inundação, a radiação solar constitui-se no recurso determinante da produtividade, já que a disponibilidade de recursos do solo geralmente não é limitante à cultura. Assim, os genótipos que formaram dossel mais denso aos 60 DAS conseguiram utilizar mais intensamente o recurso luz, sombreando as plantas da simuladora de arroz-vermelho.

De acordo com Ngouajio et al. (2001), em tomate, a elevada capacidade de captação de luz e sombreamento é fator importante para aumentar a competitividade da cultura com Abutilon theophrasti. Por isso, os autores indicaram que a velocidade de incremento em área foliar é a principal característica que deve ser 
considerada na seleção de genótipos de tomate competitivos com plantas daninhas. A elevada velocidade de expansão da área foliar foi, igualmente, fator fundamental para o sucesso competitivo de Festuca arundinacea (festuca) em relação a $A$. theophrasti (Forcella, 1987).

Tabela 1 - Coeficientes de determinação $\left(\mathrm{r}^{2}\right)$ das equações de regressão ajustadas pelas variáveis independentes, tendo redução percentual do rendimento de grãos de oito cultivares de arroz irrigado decorrente de competição de simuladora de arrozvermelho (EEA 406) como variável dependente do modelo linear múltiplo. EEA/IRGA, Cachoeirinha-RS, 2000/01

\begin{tabular}{|c|c|c|c|c|c|c|c|}
\hline \multicolumn{4}{|c|}{ Variáveis independentes do modelo ${ }^{\underline{1}}$} & \multicolumn{4}{|c|}{$r^{2}$} \\
\hline $\begin{array}{l}\text { Cobertura }{ }^{2 /} \\
\left(60 \mathrm{DAS}^{3 /}\right)\end{array}$ & & & & & & & 0,47 \\
\hline $\begin{array}{l}\text { Cobertura } \\
(60 \text { DAS })\end{array}$ & $\begin{array}{l}\text { Massa }^{4} \\
\text { (15 DAS) }\end{array}$ & & & & & & 0,50 \\
\hline $\begin{array}{l}\text { Cobertura } \\
(60 \text { DAS })\end{array}$ & $\begin{array}{l}\text { Clorofila }{ }^{-5} \\
(50 \text { DAS })\end{array}$ & $\begin{array}{l}\text { Altura }^{6} \\
\text { final }\end{array}$ & & & & & 0,52 \\
\hline $\begin{array}{l}\text { Cobertura } \\
\text { (60 DAS) }\end{array}$ & $\begin{array}{c}\text { Massa } \\
(15 \text { DAS })\end{array}$ & $\begin{array}{c}\text { Altura } \\
(15 \text { DAS })\end{array}$ & $\begin{array}{c}\text { Altura } \\
(60 \text { DAS })\end{array}$ & & & & 0,55 \\
\hline $\begin{array}{l}\text { Cobertura } \\
\text { (60 DAS) }\end{array}$ & $\begin{array}{c}\text { Massa } \\
(15 \text { DAS })\end{array}$ & $\begin{array}{c}\text { Altura } \\
(15 \text { DAS })\end{array}$ & $\begin{array}{c}\text { Altura } \\
(60 \text { DAS })\end{array}$ & $\mathrm{VE}^{7 /}$ & & & 0,57 \\
\hline $\begin{array}{l}\text { Cobertura } \\
\text { (60 DAS) }\end{array}$ & $\begin{array}{c}\text { Massa } \\
(15 \text { DAS })\end{array}$ & $\begin{array}{c}\text { Massa } \\
(30 \mathrm{DAS})\end{array}$ & $\begin{array}{c}\text { Altura } \\
(15 \text { DAS })\end{array}$ & $\begin{array}{c}\text { Altura } \\
(60 \text { DAS })\end{array}$ & VE & & 0,59 \\
\hline $\begin{array}{l}\text { Cobertura } \\
\text { (60 DAS) }\end{array}$ & $\begin{array}{l}\text { Massa } \\
\text { (15 DAS) }\end{array}$ & $\begin{array}{l}\text { Massa } \\
\text { (30DAS) }\end{array}$ & $\begin{array}{c}\text { Altura } \\
(15 \text { DAS })\end{array}$ & $\begin{array}{c}\text { Altura } \\
(60 \text { DAS })\end{array}$ & VE & $\begin{array}{c}\text { Área foliar } \\
\text { (60DAS) }\end{array}$ & 0,61 \\
\hline
\end{tabular}

$\frac{1}{2}$ Referem-se às características dos cultivares de arroz; ${ }^{2}$ Cobertura do solo; ${ }^{3 /}$ DAS= Dias após semeadura; ${ }^{4 /}$ Massa seca da parte aérea; ${ }^{5 /}$ Teor de clorofila foliar; ${ }^{6 /}$ Altura de planta; $\mathrm{e}^{\underline{7}}$ Velocidade de emergência.

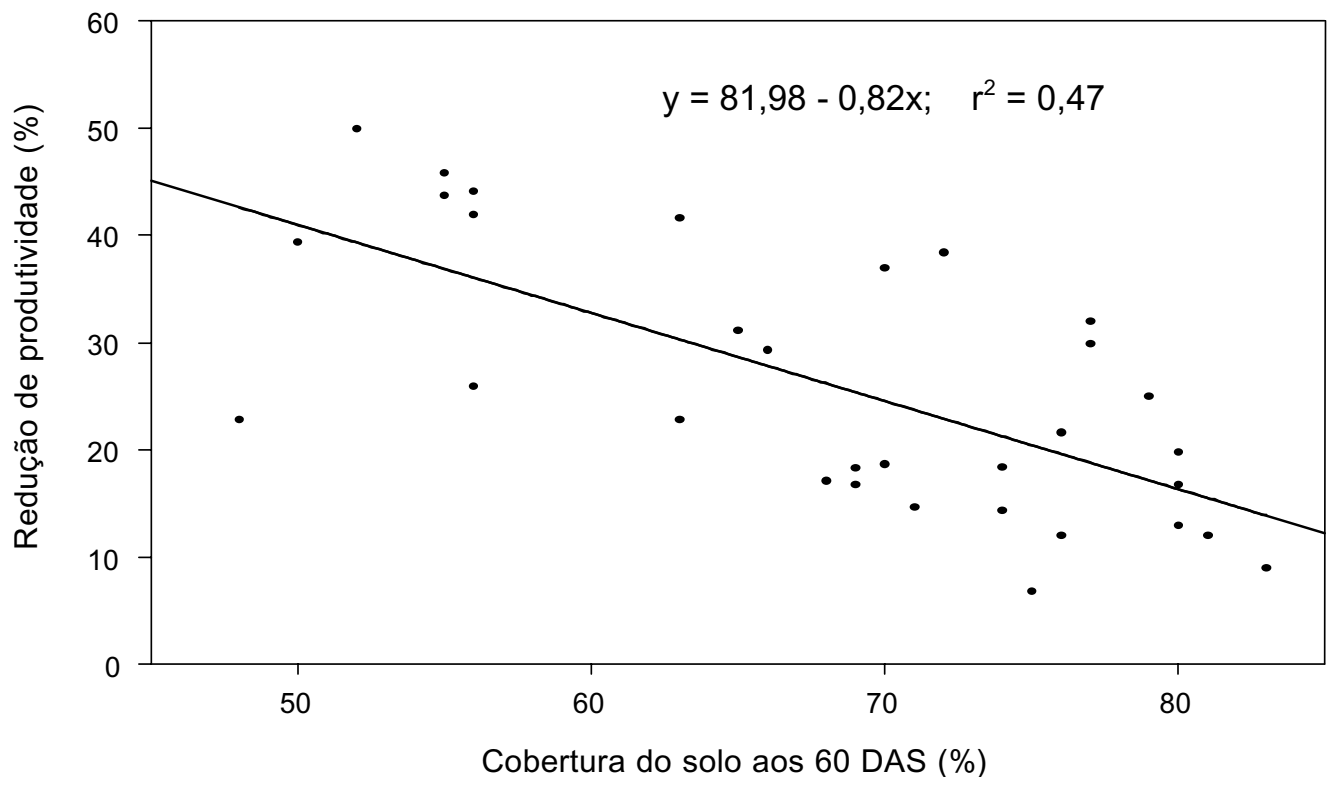

Figura 1 - Relação entre cobertura do solo proporcionada pelas plantas de oito cultivares de arroz irrigado aos 60 dias após semeadura (DAS) e redução do rendimento de grãos dos cultivares decorrente da competição de simuladora (EEA 406) de arroz-vermelho. EEA/IRGA, Cachoeirinha-RS, 2000/01. 
Tabela 2 - Coeficientes de determinação $\left(\mathrm{r}^{2}\right)$ das equações de regressão ajustadas pelas variáveis independentes, tendo a produção de massa seca da parte aérea pela simuladora de arroz-vermelho (EEA 406) em competição com oito cultivares de arroz irrigado como variável dependente do modelo linear múltiplo. EEA/IRGA, Cachoeirinha-RS, 2000/01

\begin{tabular}{|c|c|c|c|c|c|c|c|}
\hline \multicolumn{4}{|c|}{ Variáveis independentes do modelo ${ }^{1 /}$} & \multicolumn{4}{|c|}{$r^{2}$} \\
\hline $\begin{array}{l}\text { Cobertura }{ }^{2 /} \\
\left(60 \mathrm{DAS}^{3 /}\right)\end{array}$ & & & & & & & 0,64 \\
\hline $\begin{array}{l}\text { Cobertura } \\
(60 \text { DAS })\end{array}$ & $\begin{array}{c}\text { Altura }^{-4} \\
\text { final }\end{array}$ & & & & & & 0,66 \\
\hline $\begin{array}{l}\text { Cobertura } \\
\text { (60 DAS) }\end{array}$ & $\begin{array}{c}\text { Área } \\
\left(45 \mathrm{DAS}^{\frac{5}{}}\right)\end{array}$ & $\begin{array}{c}\text { Massa }^{6} \\
(45 \text { DAS })\end{array}$ & & & & & 0,68 \\
\hline $\begin{array}{l}\text { Cobertura } \\
(60 \text { DAS })\end{array}$ & $\begin{array}{c}\text { Área } \\
(45 \text { DAS })\end{array}$ & $\begin{array}{c}\text { Massa } \\
(45 \text { DAS })\end{array}$ & $\begin{array}{l}\text { Duração do } \\
\text { ciclo }\end{array}$ & & & & 0,71 \\
\hline $\begin{array}{l}\text { Cobertura } \\
(60 \text { DAS })\end{array}$ & $\begin{array}{c}\text { Área } \\
(45 \text { DAS })\end{array}$ & $\begin{array}{c}\text { Massa } \\
(45 \text { DAS })\end{array}$ & $\begin{array}{l}\text { Cobertura } \\
\text { (45 DAS) }\end{array}$ & $\begin{array}{c}\text { Altura } \\
\text { final }\end{array}$ & & & 0,73 \\
\hline $\begin{array}{l}\text { Cobertura } \\
\text { (60 DAS) }\end{array}$ & $\begin{array}{c}\text { Área } \\
(45 \mathrm{DAS})\end{array}$ & $\begin{array}{c}\text { Massa } \\
(45 \text { DAS })\end{array}$ & $\begin{array}{l}\text { Cobertura } \\
\text { (45 DAS) }\end{array}$ & $\begin{array}{c}\text { Altura } \\
(45 \text { DAS })\end{array}$ & $\begin{array}{c}\text { Altura } \\
(60 \text { DAS })\end{array}$ & & 0,76 \\
\hline $\begin{array}{l}\text { Cobertura } \\
(60 \text { DAS) }\end{array}$ & $\begin{array}{c}\text { Área } \\
\text { (45 DAS) }\end{array}$ & $\begin{array}{c}\text { Massa } \\
\text { (45 DAS) }\end{array}$ & $\begin{array}{l}\text { Cobertura } \\
\text { (45 DAS) }\end{array}$ & $\begin{array}{c}\text { Altura } \\
\text { (45 DAS) }\end{array}$ & $\begin{array}{c}\text { Altura } \\
\text { (60 DAS) }\end{array}$ & $\begin{array}{c}\text { Área } \\
(45 \mathrm{DAS})\end{array}$ & 0,77 \\
\hline
\end{tabular}

${ }^{1 /}$ Referem-se às características dos cultivares de arroz; ${ }^{2} /$ Cobertura do solo; ${ }^{3 /}$ DAS = Dias após semeadura; ${ }^{4 /}$ Altura de planta; ${ }^{5 /}$ Área foliar; e ${ }^{6 /}$ Massa seca da parte aérea.

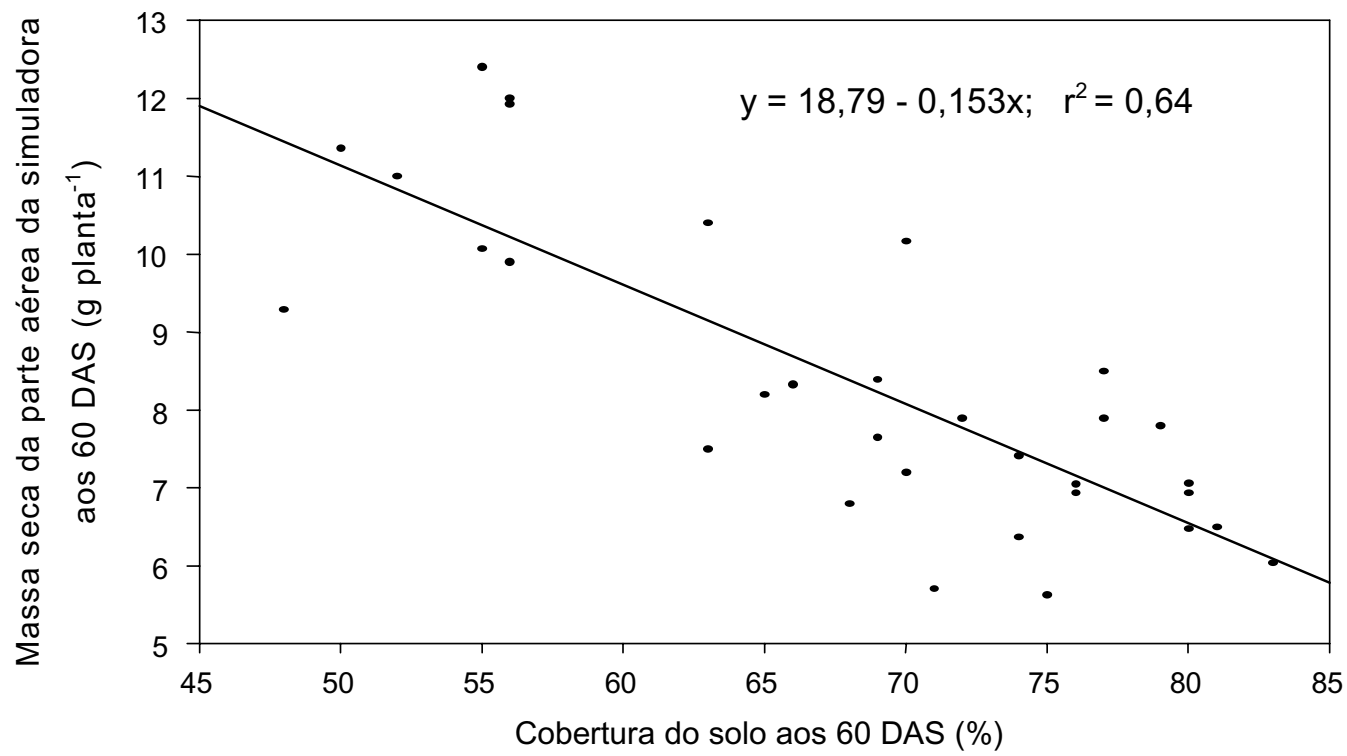

Figura 2 - Relação entre cobertura do solo proporcionada pelas plantas de oito cultivares de arroz irrigado aos 60 dias após semeadura (DAS) e massa seca da parte aérea de simuladora (EEA 406) de arroz-vermelho aos 60 DAS EEA/IRGA, Cachoeirinha-RS, 2000/01.

Salienta-se que o potencial de sombreamento proporcionado pelas plantas não é decorrente somente do acúmulo de área foliar. Outras características de planta interferem diretamente sobre essa variável, dentre as quais se destacam altura de planta, número e distribuição das folhas no dossel, ângulo foliar e decumbência do limbo (Begna et al., 2001). 
Segundo esses autores, o melhoramento vegetal que permitiu aumentar a densidade de plantas e a produtividade dos cultivos trouxe, como conseqüência, alterações morfológicas nas plantas. Em geral, buscou-se selecionar plantas com elevado ângulo foliar, com o objetivo de facilitar a penetração de luz no dossel, mantendo as folhas próximas ao solo fotossinteticamente ativas. Entretanto, a luz que chega à base do dossel também pode ser utilizada e, assim, beneficiar o crescimento de plantas daninhas.

Na prática, é difícil realizar-se a seleção de genótipos para habilidade de cobertura do solo, porque essa caracteristica depende de outras variáveis morfofisiológicas. Portanto, é indispensável determinar qual característica morfológica ou fisiológica possua maior contribuição na determinação do potencial de cobertura do solo pelos cultivares. Para isso, procedeu-se à análise de regressão linear múltipla adicional, através da qual se constatou que o acúmulo de massa seca na parte aérea dos cultivares de arroz aos 15 DAS explicou cerca de $66 \%$ das variações em cobertura do solo proporcionada pelas plantas de arroz aos 60 DAS (Tabela 3). Desse modo, há tendência de aumento linear da cobertura do solo proporcionada pelos genótipos da cultura com o incremento de massa acumulada aos 15 DAS pelas plantas de arroz (Figura 3).

Em arroz irrigado, Ni et al. (2000) chegaram a resultados semelhantes, em que a velocidade de acúmulo de massa seca da parte aérea pelas plantas de arroz até o início do afilhamento (cerca de 35 DAS) foi a variável que predisse com maior confiabilidade o acúmulo de massa seca pelas plantas daninhas. Paralelamente, Fofana \& Rauber (2000) determinaram que os acúmulos de massa radicular e aérea correlacionaram-se negativamente com a massa acumulada pelas plantas daninhas. Em outra pesquisa, Gaudet $\&$ Keddy (1988) relataram que a massa acumulada por plantas de 44 espécies explicou $63 \%$ das variações em habilidade competitiva das espécies estudadas. Por outro lado, Hucl (1997) averiguou que a capacidade de afilhamento, em cultivares de trigo, foi importante na definição da sua competitividade.

Nesse sentido, a identificação das características mais relevantes na definição do potencial competitivo dos genótipos cultivados dependerá tanto das espécies cultivadas e daninhas que convivem na comunidade, como das condições do ambiente em que elas crescem. Além disso, o primeiro requisito para o sucesso competitivo de genótipos cultivados é sua adaptação ao ambiente (Lemerle et al., 2001).

Em relação ao grau de associação entre as variáveis investigadas, verificou-se correlação elevada e positiva entre massa seca da parte aérea apresentada pela simuladora de arrozvermelho aos 60 DAS e redução do rendimento de grãos dos cultivares de arroz (Tabela 4). Isso demonstra que o crescimento elevado de plantas concorrentes geralmente reflete-se em reduções acentuadas no rendimento de grãos dos cultivos. Assim, a massa acumulada pela simuladora aos 60 DAS e a redução de rendimento de grãos dos genótipos em resposta à competição representam variáveis que expressam sua habilidade em competir com infestantes. Observa-se que essas duas variáveis apresentam associação consistente com a cobertura do solo proporcionada pelo arroz aos 60 DAS, concordando com os resultados obtidos pela análise de regressão linear múltipla.

Destaca-se, ainda, a associação significativa entre massa seca da parte aérea dos cultivares aos 15 DAS e cobertura do solo proporcionada pela cultura aos 60 DAS (Tabela 4). Todavia, outras variáveis morfológicas de início do ciclo também apresentaram forte associação com cobertura do solo aos 60 DAS, dentre elas: velocidade de emergência, altura de planta aos 15 DAS e área foliar acumulada até os 30 DAS. Esses resultados indicam que o crescimento rápido da planta conferir-lhe-á mais tarde elevado potencial de sombrear as plantas daninhas e, conseqüentemente, garantirá manutenção do potencial de rendimento, mesmo sob presença de plantas daninhas.

Ao examinar a Tabela 4, verifica-se que, em especial para as características área foliar, altura de planta e massa seca da parte aérea, ocorreram associações muito maiores em relação a cobertura de solo, massa aérea acumulada pela simuladora e redução de produtividade dos cultivares na avaliação de 15 DAS. Depois disso, gradativamente, as associações diminuíram ou não existiram. Os cultivares que apresentaram plantas com maiores área de folhas, altura e massa seca da parte aérea no início do ciclo foram aqueles que se mostraram mais competitivos.

Planta Daninha, Viçosa-MG, v.21, n.2, p.165-174, 2003 
Tabela 3 - Coeficientes de determinação $\left(\mathrm{r}^{2}\right)$ das equações de regressão ajustadas pelas variáveis independentes, tendo cobertura do solo por oito cultivares de arroz irrigado aos 60 dias após semeadura (DAS) como variável dependente do modelo linear múltiplo. EEA/IRGA, Cachoeirinha-RS, 2000/01

\begin{tabular}{|c|c|c|c|c|c|c|c|}
\hline \multicolumn{4}{|c|}{ Variáveis independentes do modelo ${ }^{1 /}$} & \multicolumn{4}{|c|}{$r^{2}$} \\
\hline $\begin{array}{c}\text { Massa }^{2} / \\
\left(15 \mathrm{DAS}^{3 /}\right)\end{array}$ & & & & & & & 0,66 \\
\hline $\mathrm{VE}^{4 /}$ & $\begin{array}{c}\text { Área }^{5 /} \\
(60 \text { DAS })\end{array}$ & & & & & & 0,74 \\
\hline $\begin{array}{c}\text { Massa } \\
(15 \text { DAS })\end{array}$ & VE & $\begin{array}{c}\text { Área } \\
(30 \text { DAS })\end{array}$ & & & & & 0,77 \\
\hline $\begin{array}{l}\text { Massa } \\
(15 \text { DAS })\end{array}$ & VE & $\begin{array}{c}\text { Área } \\
(30 \text { DAS) }\end{array}$ & $\begin{array}{l}\text { Altura }^{-} \\
\text {(60 DAS) }\end{array}$ & & & & 0,80 \\
\hline $\begin{array}{c}\text { Massa } \\
(15 \mathrm{DAS})\end{array}$ & VE & $\begin{array}{c}\text { Área } \\
(30 \text { DAS })\end{array}$ & $\begin{array}{c}\text { Altura } \\
(30 \text { DAS })\end{array}$ & $\begin{array}{c}\text { Altura } \\
(60 \text { DAS })\end{array}$ & & & 0,82 \\
\hline $\begin{array}{c}\text { Massa } \\
(15 \text { DAS })\end{array}$ & $\begin{array}{c}\text { Área } \\
(60 \text { DAS })\end{array}$ & VE & $\begin{array}{c}\text { Área } \\
(30 \mathrm{DAS})\end{array}$ & $\begin{array}{c}\text { Área } \\
(60 \text { DAS })\end{array}$ & $\begin{array}{c}\text { Altura } \\
(45 \text { DAS })\end{array}$ & & 0,83 \\
\hline $\begin{array}{c}\text { Massa } \\
\text { (15 DAS) }\end{array}$ & $\begin{array}{c}\text { Área } \\
(60 \text { DAS })\end{array}$ & VE & $\begin{array}{c}\text { Área } \\
(30 \mathrm{DAS})\end{array}$ & $\begin{array}{c}\text { Área } \\
(60 \text { DAS })\end{array}$ & $\begin{array}{c}\text { Altura } \\
(45 \text { DAS) }\end{array}$ & $\begin{array}{c}\text { Altura } \\
\text { (60 DAS) }\end{array}$ & 0,84 \\
\hline
\end{tabular}

${ }^{1 /}$ Referem-se às características dos cultivares de arroz; ${ }^{2 /}$ Massa seca da parte aérea; ${ }^{3 /} \mathrm{DAS}=$ Dias após semeadura; ${ }^{4 /}$ Velocidade de

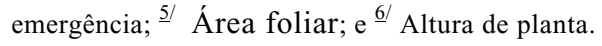

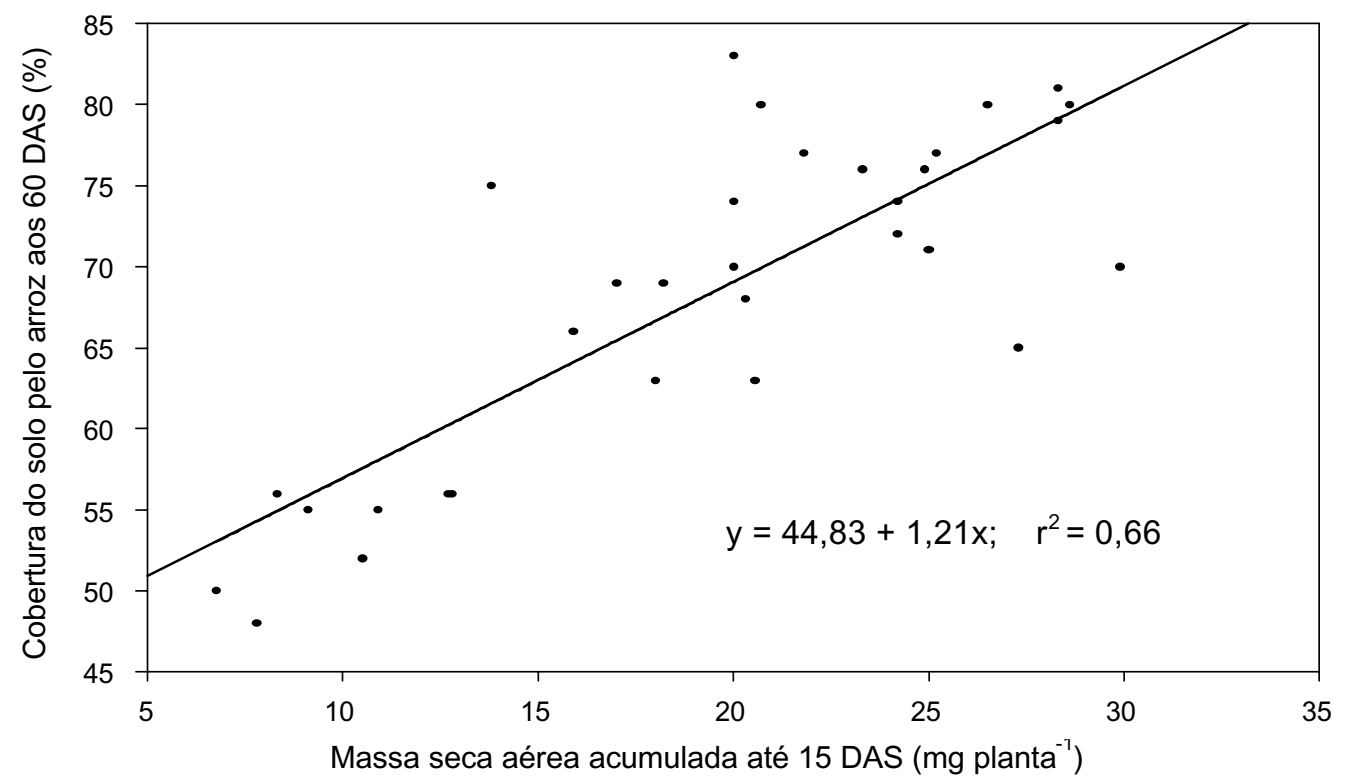

Figura 3 - Relação entre massa seca da parte aérea acumulada por planta aos 15 dias após semeadura (DAS) e cobertura do solo proporcionada por oito cultivares de arroz irrigado aos 60 DAS. EEA/IRGA, Cachoeirinha-RS, 2000/01.

Detectou-se forte associação negativa entre cobertura do solo aos 60 DAS e penetração de luz através do dossel (Tabela 4), confirmando que cultivares que apresentam maior capacidade em cobrir o solo também permitem menor disponibilidade de luz para plantas concorrentes. Em adição, constatou-se não haver associação entre duração do ciclo de desenvolvimento do arroz e da altura final de planta com redução de rendimento de grãos dos cultivares 
e massa apresentada pela simuladora de arrozvermelho aos 60 DAS (Tabela 4). Ainda, observou-se não existir correlação entre produtividade de grãos em situação livre da competidora e redução de rendimento de grãos decorrente da interferência daquela (Tabela 4), demonstrando haver a possibilidade de obtenção de genótipos de arroz que apresentem simultaneamente elevado potencial produtivo e competitivo.
A capacidade de plantas de arroz irrigado em sombrear o solo aos 60 dias após a semeadura é a característica que confere maior habilidade ao genótipo em competir com simuladora de arroz-vermelho, estando ela associada ao acúmulo de massa seca da parte aérea pelas plantas da cultura aos 15 dias após a semeadura. Nesse sentido, a velocidade de acúmulo de massa na parte aérea de genótipos de arroz irrigado na fase inicial de crescimento é

Tabela 4 - Coeficientes de correlação linear simples entre variáveis analisadas em experimento que avaliou características de oito cultivares de arroz irrigado em resposta à presença da simuladora. (EEA 406) de arroz-vermelho. EEA/IRGA, Cachoeirinha-RS, 2000/01

\begin{tabular}{|c|c|c|c|}
\hline Características de genótipos de arroz & $\begin{array}{l}\text { Cobertura do solo } \\
\text { pelos cultivares } \\
(60 \mathrm{DAS})^{1 /}\end{array}$ & $\begin{array}{c}\text { Massa seca da parte } \\
\text { aérea da simuladora } \\
\text { (60 DAS) }\end{array}$ & $\begin{array}{l}\text { Redução (\%) de } \\
\text { produtividade dos } \\
\text { cultivares }\end{array}$ \\
\hline Velocidade de emergência & $0,74 * *$ & $-0,54 * *$ & $-0,41 *$ \\
\hline Área foliar (15 DAS) & $0,80 * *$ & $-0,63 * *$ & $-0,47 * *$ \\
\hline Área foliar (30 DAS) & $0,75 * *$ & $-0,57 * *$ & $-0,43 *$ \\
\hline Área foliar (45 DAS) & $0,53 * *$ & $-0,53 * *$ & $-0,39 *$ \\
\hline Área foliar (60 DAS) & $0,50 * *$ & $-0,44 *$ & $-0,39 *$ \\
\hline Estádio de desenvolvimento (15 DAS) & $0,40 *$ & $-0,19 \mathrm{~ns}$ & $-0,22 \mathrm{~ns}$ \\
\hline Estádio de desenvolvimento (30 DAS) & $0,59 * *$ & $-0,44 *$ & $-0,24 \mathrm{~ns}$ \\
\hline Estádio de desenvolvimento (45 DAS) & $0,33 \mathrm{~ns}$ & $-0,06 \mathrm{~ns}$ & $-0,26 \mathrm{~ns}$ \\
\hline Estádio de desenvolvimento (60 DAS) & $0,35 *$ & $-0,34 \mathrm{~ns}$ & $-0,06 \mathrm{~ns}$ \\
\hline Altura de planta (15 DAS) & $0,70 * *$ & $-0,60 * *$ & $-0,45 \mathrm{~ns}$ \\
\hline Altura de planta (30 DAS) & $0,35 *$ & $-0,32 \mathrm{~ns}$ & $-0,20 \mathrm{~ns}$ \\
\hline Altura de planta (45 DAS) & $0,37 *$ & $-0,37 *$ & $-0,23 \mathrm{~ns}$ \\
\hline Altura de planta (60 DAS) & $0,20 \mathrm{~ns}$ & $-0,15 \mathrm{~ns}$ & $0,01 \mathrm{~ns}$ \\
\hline Altura na colheita & $-0,07 \mathrm{~ns}$ & $0,18 \mathrm{~ns}$ & $0,13 \mathrm{~ns}$ \\
\hline Massa seca da parte aérea (15 DAS) & $0,80 * *$ & $-0,67 * *$ & $-0,45 * *$ \\
\hline Massa seca da parte aérea (30 DAS) & $0,67 * *$ & $-0,51 * *$ & $-0,36 *$ \\
\hline Massa seca da parte aérea (45 DAS) & $0,40 *$ & $-0,34 \mathrm{~ns}$ & $-0,24 \mathrm{~ns}$ \\
\hline Massa seca da parte aérea (60 DAS) & $0,26 \mathrm{~ns}$ & $-0,26 \mathrm{~ns}$ & $-0,17 \mathrm{~ns}$ \\
\hline Teor de clorofila foliar (50 DAS) & $-0,47 * *$ & $0,38 *$ & $0,18 \mathrm{~ns}$ \\
\hline Cobertura do solo (45 DAS) & $0,91 * *$ & $-0,69 * *$ & $-0,61 * *$ \\
\hline Cobertura do solo (60 DAS) & - & $-0,80 * *$ & $-0,68 * *$ \\
\hline Penetração de luz no dossel & $-0,81 * *$ & $0,65 * *$ & $0,48 * *$ \\
\hline Duração do ciclo & $-0,02 \mathrm{~ns}$ & $0,13 \mathrm{~ns}$ & $-0,02 \mathrm{~ns}$ \\
\hline Produtividade livre de infestação & $0,37 *$ & $-0,35 *$ & $-0,20 \mathrm{~ns}$ \\
\hline Produtividade sob infestação & $0,67 * *$ & $-0,74 * *$ & $-0,70 * *$ \\
\hline Redução de produtividade & $-0,68 * *$ & $0,88 * *$ & - \\
\hline Massa seca da parte aérea da simuladora (60 DAS) & $-0,80 * *$ & - & $0,88 * *$ \\
\hline
\end{tabular}

${ }^{1}$ Dias após semeadura; ** Coeficientes significativos a $1 \%$ de probabilidade; * Coeficientes significativos a $5 \%$ de probabilidade; e ns Coeficientes não-significativos. 
característica indicadora de elevada competitividade com plantas concorrentes. Nesta pesquisa também se constatou que a altura final de planta e a duração do ciclo de desenvolvimento do cultivar de arroz não apresentam associação com o potencial competitivo do genótipo.

\section{LITERATURA CITADA}

AGOSTINETTO, D. et al. Arroz vermelho: ecofisiologia e estratégias de controle. Ci. Rural, v. 31, p. 341-349, 2001.

BEGNA, S. H. et al. Morphology and yield response to weed pressure by corn hybrids differing in canopy architecture. Eur. J. Agron., v. 14, p. 293-302, 2001.

BENNETT, A. C.; SHAW, D. R. Effect of Glycine max cultivar and weed control on weed seed characteristics. Weed Sci., v. 48, p. 431-435, 2000.

FIRBANK, L. G.; WATKINSON, A. R. On the analysis of competition within two-species mixtures of plants. J. Appl. Ecol., v. 22, p. 503-517, 1985.

FOFANA, B.; RAUBER, R. Weed suppression ability of upland rice under low-input conditions in West Africa. Weed Res., v. 40, p. 271-280, 2000.

FORCELLA, F. Tolerance of weed competition associated with high leaf-area expansion rate in tall fescue. Crop Sci., v. 27, p. 146-147, 1987.

GARRITY, D. P.; MOVILLON, M.; MOODY, K. Differential weed suppression ability in upland rice cultivars. Agron. J., v. 84, p. 586-591, 1992.

GAUDET, C. L.; KEDDY, P. A. A comparative approach to predicting competitive ability from plant traits. Nature, v. 334, p. 242-243, 1988.

HAUN, J. R. Visual quantification of wheat development. Agron. J., v. 65, p. 116-119, 1973.
HORAK, M. J.; LOUGHIN, T. M. Growth analysis of four Amaranthus species. Weed Sci., v. 48, p. 347-355, 2000.

HUCL, P. Response to weed control by four spring wheat genotypes differing in competitive ability. Can. J. Plant Sci., v. 78, p. 171-173, 1997.

JANNINK, J. L. et al. Index selection for weed suppressive ability in soybean. Crop Sci., v. 40, p. 1087-1094, 2000.

LEMERLE, D.; VERBEEK, B.; ORCHARD, B. Ranking the ability of wheat varieties to compete with Lolium rigidum. Weed Res., v. 41, p. 197-209, 2001.

NGOUAJIO, M.; McGIFFEN JR., M. E.; HEMBREE, K. J. Tolerance of tomato cultivars to velvetleaf interference. Weed Sci., v. 49, p. 91-98, 2001.

NI, H. et al. Oryza sativa plant traits conferring competitive ability against weeds. Weed Sci., v. 48, p. 200-204, 2000.

POPINIGIS, F. Fisiologia da semente. Brasília: AGIPLAN, 1977. 289 p.

RADOSEVICH, S.; HOLT, J.; GHERSA, C. Weed ecology. 2.ed. New York: Wiley, 1997. 588 p.

ROMAN, E. S. et al. Modeling germination and seedling elongation of common lambsquarters (Chenopodium album). Weed Sci., v. 47, p. 149-155, 1999.

SAS INSTITUTE - Institute Statistical Analysis System. User's guide. Version 6. 4.ed., Cary: 1989. 846 p.

SATORRE, E. H.; SNAYDON, R. W. A comparison of root and shoot competition between spring cereals and Avena fatua L. Weed Res., v. 32, p. 45-55, 1992.

SEEFELDT, S. S.; OGG JR., A. G.; HOU, Y. Near-isogenic lines for Triticum aestivum height and crop competitiveness. Weed Sci., v. 47, p. 316-320, 1999.

SEIBERT, A. C.; PEARCE, R. B. Growth analysis of weed and crop species with reference to seed weight. Weed Sci., v. 41, p. $52-56,1993$. 